\title{
EFEITO DE REGULADORES DE CRESCIMENTO, APLICADOS EM DIFERENTES ÉPOCAS, E DA INCISÃO ANELAR DOS RAMOS PRINCIPAIS SOBRE A PRODUÇÃO DA LARANJEIRA DE UMBIGO 'MONTE PARNASO'
}

\section{PRODUCTION OF 'MONTE PARNASO' NAVEL ORANGES IN FUNCTION OF THE APPLICATION OF GROWTH REGULATORS AND GIRDLING}

\author{
Gilmar Schäfer ${ }^{2}$ Otto Carlos Koller ${ }^{3}$ Ivar Antônio Sartori ${ }^{2}$ Michel Elias Casali ${ }^{4}$ \\ Jurandir Gonçalves de Lima ${ }^{5}$
}

\section{RESUMO}

\begin{abstract}
Com o propósito de reduzir a queda prematura de frutos e aumentar a produção de laranjeiras de umbigo 'Monte Parnaso' (Citrus sinensis [L.] Osbeck), no ano agrícola de 1997/98, plantas com seis anos de idade, enxertadas sobre Poncirus trifoliata (L.) Raf., de um pomar comercial, da empresa Panorama Citros, situado no Município de Butiá, Estado do Rio Grande do Sul foram pulverizadas com os seguintes tratamentos: T1) Testemunha; T2) 5ppm de $\mathrm{AG}_{3}$ no final da queda das pétalas, em setembro de 1988; T3) Incisão anelar da casca dos ramos principais 10 dias após a floração, em setembro de 1988; T4) Idem T2 + T3; T5) 15ppm de 2,4-D em novembro de 1988; T6) Idem T4 + T5; T7) Incisão anelar da casca dos ramos principais em novembro de 1988; T8) Idem 5 + 7; T9) Idem T6 + T7; T10) Idem $T 6+10$ ppm de $A_{3}$ com 15ppm de 2,4-D em maio de 98; T11) Idem $T 9+10 \mathrm{ppm}$ de $A G_{3}$ e 15ppm de 2,4-D em maio de 1988. O delineamento experimental adotado foi em blocos ao acaso, com quatro repetições usando-se três plantas úteis por parcela. Todos os tratamentos em relação a testemunha promoveram um aumento na ordem de $45 \%$ na produção de frutas em número e peso. O peso médio, sólidos solúveis totais, acidez total titulável e a percentagem de suco nos frutos não foram afetados significativamente.
\end{abstract}

Palavras-chave: Citrus sinensis, reguladores de crescimento, incisão anelar, queda de frutos, retenção de frutos.

\section{SUMMARY}

The present trial was carried out aiming to increase fruit set of 'Monte Parnaso' (Citrus sinensis [L.] Osbeck) navel oranges budded on trifoliate orange (Poncirus trifoliata [L.] Raf.) rootstocks grown in the State of Rio Grande do Sul, Brazil. In 1996, six-year-old navel orange trees were sprayed with growth regulators combined or not with girdling. The following treatments $(\boldsymbol{T})$ was conducted: $\boldsymbol{T 1})$ Control; $\boldsymbol{T} 2)$ spraying of five ppm of $\mathrm{GA}_{3}$ at the end of petal fall; T3) girdling 10 days after petal fall; T4) T2 plus T3; T5) spraying of 15ppm 2.4-D; T6) T4 plus T5; T7) girdling in November $15^{\text {th }}$; T8) T5 plus T7; T9) T6 plus T7; T10) T6 plus spraying of 10ppm of GA, and 15ppm of 2.4-D in May of 1998; T11) T9 plus spraying of 10ppm of $\mathrm{GA}_{3}$ and 15ppm 2.4-D in May of 1998. The results showed increased the weight $(45 \%)$ and number of fruits produced. The treatments did not affect the fruits average and total soluble solids, titratable total acidity and percentage of juice contents.

Key words: Citrus sinensis, girdling, growth regulator, fruit drop, fruit set.

\section{INTRODUÇÃO}

O Brasil, dentro do contexto mundial, é o maior produtor de frutas cítricas, com uma produção que, segundo a FAO (1998), ultrapassa 23 milhões de toneladas. Deste montante, a produção principal é de laranjas, com predominância das cultivares 'Pêra', 'Natal' e 'Valência'; em menor escala, são produzidas as laranjas 'Hamlin', 'Lima' e do tipo umbigo ('Bahia', 'Baianinha' e 'Monte Parnaso'). O Rio Grande do Sul é o terceiro maior produtor de citros do Brasil (IBGE, 1996), destacando-se

\footnotetext{
${ }^{1}$ Trabalho financiado pela FINEP, CNPq, UFRGS e FAPERGS.

${ }^{2}$ Engenheiro Agrônomo, aluno do Programa de Pós-graduação em Fitotecnia, Faculdade de Agronomia, Universidade Federal do Rio Grande do Sul (UFRGS). E-mail: schafer@vortex.ufrgs.br.

${ }^{3}$ Engenheiro Agrônomo, Professor Adjunto, Faculdade de Agronomia, UFRGS, Departamento de Horticultura e Silvicultura, CP 77, 90001-970, Porto Alegre, RS. Bolsista do CNPq. E-mail: ockoller@adufrgs.ufrgs.br. Autor para correspondência.

${ }^{4}$ Aluno da Faculdade de Agronomia, UFRGS. Bolsista de Iniciação Científica.

${ }^{5}$ Técnico Agrícola, funcionário da Panoramas Citrus, Butiá - RS.
} 
principalmente pela produção de frutos de mesa, como as tangerinas 'Montenegrina' e 'Caí' e laranjas de umbigo 'Bahia' e 'Monte Parnaso'. Dentre as laranjeiras de umbigo, a 'Monte Parnaso' é a mais cultivada, principalmente porque os frutos são grandes e de colheita tardia (agosto a outubro). Entretanto, ela apresenta baixa produtividade, atingindo, em geral, apenas $1 / 3$ a $1 / 4$ da produtividade alcançada pela laranjeira 'Valência' (KOLLER, 1993).

As variedades sem sementes, como as laranjeiras de umbigo, estão mais sujeitas à queda de frutos, atribuída principalmente a desequilíbrios hormonais e nutricionais (AGUSTÍ \& ALMELA, 1991). Variações de temperatura ou qualquer outro estresse, durante ou depois da queda natural de frutinhos, pode acentuar a abscisão dos mesmos (EL-OTMANI, 1992). Para PRIMO-MILLO (1993), os fatores que condicionam a fixação de frutos são a disponibilidade de nutrientes, disponibilidade hídrica e os níveis hormonais. Todos os fatores que estimulam o crescimento inicial do ovário aumentam a fixação de frutos (ZUCCONI et al., 1978).

A aplicação de ácido giberélico $\left(\mathrm{AG}_{3}\right)$ estimula a formação de folhas novas e aumenta a sua superfície, conseqüentemente incrementa a síntese de fotoassimilados (AGUSTÍ \& ALMELA, 1991 e PRIMO-MILLO, 1993), com isso, ocorre um aumento na translocação de nutrientes minerais e fotoassimilados das folhas adjacentes para a flor e o fruto em desenvolvimento.

Trabalhos testando a eficiência do ácido giberélico foram conduzidos por MOSS (1972) que cita que o $\mathrm{AG}_{3}$, aplicado na dose de 10ppm durante a floração, em cultivares de frutos sem sementes como a tangerineira 'Clementina', aumenta a fixação de frutinhos. RAGONE (1992), na Argentina, conseguiu aumentar em 16,8\% a produtividade da tangerineira 'Ellendale' com 10ppm de $\mathrm{AG}_{3}$ aplicados quando $75 \%$ dos botões florais estavam abertos.

O 2,4-D (ácido 2,4 - diclorofenoxiacético) é um produto sintético que exerce ação hormonal. Bravo, apud COELHO et al. (1978), relata que o uso de 2,4-D chegou a reduzir a queda de laranjas 'Bahia' em 56\%. Pulverizações com 10ppm de 2,4$\mathrm{D}$, quando as flores perdem as pétalas, aumentaram a fixação e o tamanho dos frutos em laranjeiras 'Washington Navel' (García-Martínez, apud AGUSTÍ \& ALMELA, 1991).

$\mathrm{Na}$ Espanha, para aumentar a fixação e o crescimento de frutos em laranjeiras de umbigo, AGUSTÍ \& ALMELA (1991) recomendam a pulverização foliar com 5ppm de $\mathrm{AG}_{3}$ e micronutrientes no final da queda das pétalas e 10 a
15 dias após a incisão anelar da casca dos ramos principais. $\mathrm{O}$ uso de 2,4-D aliado ao $\mathrm{AG}_{3}$, na Argentina, inibiu em até $50 \%$ a queda de frutos na pré-colheita em laranjeiras de umbigo (RAGONE, 1992).

O nível endógeno de carbohidratos não é o único fator responsável pela fixação de frutos, entretanto, em ocasiões de elevada competição na planta, pode ser um fator limitante. Com a realização de uma incisão anelar dos ramos, pode-se aumentar a fixação de frutos, através da retenção temporária na copa, dos carbohidratos que se translocariam para o sistema radicular (AGUSTÍ \& ALMELA, 1991 e AGUSTÍ et al., 1996).

O objetivo deste trabalho foi avaliar o efeito de reguladores de crescimento, aplicados em diversas épocas, e da incisão anelar dos ramos principais sobre a produção de laranjeiras de umbigo 'Monte Parnaso'.

\section{MATERIAL E MÉTODOS}

O experimento foi realizado no ano agrícola de 1997/98, com laranjeiras de umbigo 'Monte Parnaso' enxertadas sobre Poncirus trifoliata (L.) Raf, com idade de seis anos, plantadas no espaçamento de 2,5 x 6,0m, localizadas num pomar comercial da Empresa Panorama Citros, no município de Butiá, Estado do Rio Grande do Sul. O solo da área experimental é classificado como Podzólico vermelho-escuro, de textura francoargilosa.

O delineamento experimental adotado foi de blocos ao acaso, com onze tratamentos e quatro repetições. Utilizaram-se três plantas úteis por parcela e, pelo menos, uma planta de bordadura entre as parcelas, na linha de plantas.

Os tratamentos foram os seguintes: T1) Testemunha (sem reguladores de crescimento e anelagem); T2) Pulverizações com cinco ppm de ácido giberélico $\left(\mathrm{AG}_{3}\right)$ no final da queda das pétalas (25 de setembro de 1997); T3) Incisão anelar da casca dos ramos principais 10 dias após a floração (08 de outubro de 1997); T4) pulverizações com cinco ppm de $\mathrm{AG}_{3}$ em 25 de setembro de $1997+$ incisão anelar da casca dos ramos principais em 08 de outubro de 1997; T5) Pulverização de 15 ppm de ácido 2,4 - diclorofenoxiacético (2,4-D) em novembro (14 de novembro de 1997); T6) Pulverização de cinco ppm de $\mathrm{AG}_{3}$ aplicado em 25 de setembro de 1997 + incisão anelar da casca dos ramos principais em 08 de outubro de 1997 + pulverização de $15 \mathrm{ppm}$ de 2,4-D em 14 de novembro de 1997; T7) Incisão anelar da casca dos ramos principais em novembro (14 de novembro de 
1997); T8) Pulverização de 15ppm de 2,4-D (14 de novembro de 1997) + incisão anelar da casca dos ramos principais em novembro (14 de novembro de 1997); T9) Pulverização de cinco ppm de $\mathrm{AG}_{3}$ em 25 de setembro de 1997 + incisão anelar da casca dos ramos principais em 08 de outubro de $1997+$ pulverização de $15 \mathrm{ppm}$ de 2,4-D em 14 de novembro de 1997 + incisão anelar da casca dos ramos principais em 14 de novembro de 1997; T10) Pulverização de cinco ppm de $\mathrm{AG}_{3}$ em 25 de setembro de 1997 + incisão anelar da casca dos ramos principais em 08 de outubro de $1997+$ pulverização com $15 \mathrm{ppm}$ de 2,4-D em 14 de novembro de 1997 + pulverização com 10ppm de $\mathrm{AG}_{3}$ e $15 \mathrm{ppm}$ de 2,4-D em 25 de maio de 1998 (antes da queda de frutos na pré-colheita); T11) Pulverização com cinco ppm de $\mathrm{AG}_{3}$ em 25 de setembro de 1997 + incisão anelar da casca dos ramos principais em 08 de outubro de 1997 + pulverização com $15 \mathrm{ppm}$ de 2,4-D em 14 de novembro de 1997 + incisão anelar da casca dos ramos principais em 14 de novembro de $1997+$ pulverização com $10 \mathrm{ppm}$ de $\mathrm{AG}_{3}$ e $15 \mathrm{ppm}$ de $2,4-\mathrm{D}$ em 25 de maio de 98 ;

Para a realização da incisão anelar dos ramos principais, utilizou-se a metodologia descrita por AGUSTÍ \& ALMELA (1991), onde com o auxílio de uma tesoura aneladora, fez-se uma incisão anelar de $360^{\circ}$, com aproximadamente $1 \mathrm{~mm}$ de largura, cortando-se apenas a casca dos ramos, sem cortar o lenho. A fonte de $\mathrm{AG}_{3}$ utilizada foi $\mathrm{o}$ produto comercial PRO-GIBB $^{\circledR}$ da Abbott Laboratórios do Brasil LTDA. e como fonte de 2,4D usou-se o produto comercial U46 ${ }^{\circledR}$ D - FLUID 2,4-D da BASF Brasileira S.A. Para a aplicação dos reguladores de crescimento utilizou-se um pulverizador do tipo costal, com bico cônico número 12 , acionado manualmente.

A colheita dos frutos foi realizada nos dias 11 e 12 de agosto de 1998. As adubações, tratamentos fitossanitários e demais práticas culturais foram uniformes em todo o experimento. Foram avaliados o número e peso dos frutos colhidos por planta, peso médio dos frutos (peso dos frutos/número de frutos por planta) e de suas características físicas e químicas. As médias foram submetidas a análise de variância e comparadas pelo teste de Duncan ao nível de 5\% de significância.

A análise química e física dos frutos consistiu na: coleta aleatória de 10 frutos por parcela, que foram acondicionados em sacos plásticos de polipropileno e conservados em câmara fria a $7^{\circ} \mathrm{C}$ até o momento da análise no Laboratório do Departamento de Horticultura e Silvicultura da
Faculdade de Agronomia da UFRGS, determinandose a percentagem de suco em relação ao peso total dos frutos; acidez titulável total (ATT) expressa em percentagem de ácido cítrico anídrico, determinada por titulometria com solução de $\mathrm{NaOH} 0,1 \mathrm{~N}$, e sólidos solúveis totais (SST), determinado com o uso de sacarímetro.

\section{RESULTADOS E DISCUSSÃO}

Verificou-se, através de observações visuais, que após a ocorrência da queda natural de frutinhos, a qual nas laranjeiras 'Monte Parnaso' geralmente se verifica em outubro, ocorre uma segunda fase de intensa queda de frutos com 2 a $4 \mathrm{~cm}$ de diâmetro, da segunda quinzena de novembro até a primeira quinzena de dezembro. Resultados semelhantes também já foram relatados por KOLLER $\boldsymbol{e t}$ al. (1999a, 1999b) e SCHÄFER $\boldsymbol{e t}$ al . (1999). Também ocorreu uma queda de frutos maduros, nos meses que antecederam a colheita, concordando com observações feitas por RAGONE (1992). Não se observou sintomas de toxidez nas plantas, decorrentes da aplicação dos reguladores de crescimento ou da prática do anelamento, conforme constatado por KOLLER et al. (1999a).

Na tabela 1, são apresentados o número, peso e peso médio dos frutos colhidos por planta. $\mathrm{Na}$ tabela 2, são apresentados os teores de sólidos solúveis totais, acidez total titulável e a percentagem de suco presentes nos frutos.

Observa-se na tabela 1 que todos os tratamentos superaram, tanto em peso quanto em número, a produção da testemunha; entretanto os tratamentos T6 e T7 não diferiram estatisticamente da testemunha. Estes dados estão de acordo com as recomendações de AGUSTÍ \& ALMELA (1991), que preconizam a aplicação de $5 \mathrm{ppm}$ de $\mathrm{AG}_{3}$ e a incisão anelar da casca dos ramos principais no final da floração.

Em experimento realizado por SCHÄFER et al. (1999), com 'Monte Parnaso', ficou evidenciado o efeito benéfico da aplicação de $10 \mathrm{ppm}$ de $\mathrm{AG}_{3}$ na fase inicial da brotação, em agosto, seguida de cinco ppm de $\mathrm{AG}_{3}$ após a queda das pétalas e $15 \mathrm{ppm}$ de $2,4-\mathrm{D}$ e/ou incisão anelar dos ramos principais em novembro, na retenção de frutos. No entanto, não foi evidenciado qual o fator que atuou ou se todos são necessários. Os resultados desse trabalho permitiram verificar que o uso de cinco ppm de $\mathrm{AG}_{3}$, no final da queda das pétalas, ou a incisão anelar, 10 dias após a floração, ou a aplicação de $15 \mathrm{ppm}$ de 2,4-D, em novembro, foram suficientes para aumentar a produção. 
Tabela 1 - Número, peso $(\mathrm{kg})$ e peso médio (gramas) de frutos produzidos, após aplicações de reguladores de crescimento e incisão anelar da casca dos ramos principais, em laranjeira de umbigo cv. "Monte Parnaso". Butiá-RS, 1998.

\begin{tabular}{llll}
\hline Tratamentos & $\begin{array}{c}\text { Número de } \\
\text { frutos } \\
\text { colhidos }\end{array}$ & $\begin{array}{c}\text { Peso da } \\
\text { produção } \\
(\mathrm{kg})\end{array}$ & $\begin{array}{c}\text { Peso médio } \\
\text { dos frutos } \\
(\mathrm{g})\end{array}$ \\
\hline 1 - testemunha & $121 \mathrm{~d} *$ & $33,59 \mathrm{~b}$ & $278 \mathrm{a}$ \\
2 - 5ppm AG & $\begin{array}{c}\text { d no final da queda das pétalas } \\
175 \mathrm{abc}\end{array}$ & $\begin{array}{c}45,45 \mathrm{a} \\
260 \mathrm{a}\end{array}$ \\
3 - Incisão anelar 10 dias após a floração & $206 \mathrm{a}$ & $50,65 \mathrm{a}$ & $246 \mathrm{a}$ \\
4 - Idem 2 + 3 & $169 \mathrm{abc}$ & $44,15 \mathrm{a}$ & $261 \mathrm{a}$ \\
5 - 15ppm 2,4-D em novembro & $187 \mathrm{ab}$ & $45,80 \mathrm{a}$ & $245 \mathrm{a}$ \\
6 - Idem 4 + 5 & $156 \mathrm{bcd}$ & $41,85 \mathrm{ab}$ & $268 \mathrm{a}$ \\
7 - Incisão anelar em novembro & $146 \mathrm{~cd}$ & $41,55 \mathrm{ab}$ & $284 \mathrm{a}$ \\
8 - Idem 5 + 7 & $160 \mathrm{bc}$ & $44,20 \mathrm{a}$ & $276 \mathrm{a}$ \\
9 - Idem 6 + 7 & $162 \mathrm{bc}$ & $45,70 \mathrm{a}$ & $282 \mathrm{a}$ \\
10 - Idem 6 + 10ppm de AG e 15ppm 2,4-D em maio & $174 \mathrm{abc}$ & $48,25 \mathrm{a}$ & $277 \mathrm{a}$ \\
11 - Idem 9 + 10ppm de AG3 e 15ppm 2,4-D em maio & $156 \mathrm{bcd}$ & $42,70 \mathrm{a}$ & $274 \mathrm{a}$ \\
Média & 164,73 & 43,99 & 268 \\
Coeficiente de Variação (\%) & 14,62 & 12,54 & 8,52 \\
\hline
\end{tabular}

*Médias não seguidas por mesma letra, na coluna, diferem entre si, pelo teste de Duncan, em nível de $5 \%$ de probabilidade de erro.

A incisão anelar realizada em novembro, segundo o preconizado por PRIMO-MILLO (1993), não foi suficiente para aumentar a retenção de frutos a níveis significativos, o que já havia sido relatado por KOLLER et al. (1999b). Isto pode ter ocorrido pelo fato de a incisão anelar não ter proporcionado à planta a retenção de um suprimento adequado de fotoassimilados e fitorreguladores necessários ao desenvolvimento dos frutos, evidenciando assim que a fase mais crítica para a fixação e desenvolvimento dos frutos é a fase inicial, conforme o relatado por ZUCCONI et al. (1978).

Tabela 2 - Teor de sólidos solúveis totais (SST), acidez total titulável (ATT) e percentagem de suco (\% suco) dos frutos, após a aplicação de reguladores de crescimento e incisão anelar da casca dos ramos principais de laranjeira cv. "Monte Parnaso". Butiá-RS, 1998.

\begin{tabular}{llll}
\hline Tratamento & SST & ATT & $\%$ SUCO \\
\hline 1 - testemunha & $8,07 \mathrm{a} *$ & $0,91 \mathrm{a}$ & $46,78 \mathrm{a}$ \\
2 - 5ppm AG 3 no final da queda das pétalas & $7,84 \mathrm{a}$ & $0,83 \mathrm{a}$ & $46,70 \mathrm{a}$ \\
3 - Incisão anelar 10 dias após a floração & $7,62 \mathrm{a}$ & $0,89 \mathrm{a}$ & $44,87 \mathrm{a}$ \\
4 - Idem 2 + 3 & $7,19 \mathrm{a}$ & $0,92 \mathrm{a}$ & $47,14 \mathrm{a}$ \\
5 - 15ppm 2,4-D em novembro & $7,74 \mathrm{a}$ & $0,80 \mathrm{a}$ & $44,01 \mathrm{a}$ \\
- Idem 4 + 5 & $7,30 \mathrm{a}$ & $0,93 \mathrm{a}$ & $47,18 \mathrm{a}$ \\
7 - Incisão anelar em novembro & $7,66 \mathrm{a}$ & $0,84 \mathrm{a}$ & $44,04 \mathrm{a}$ \\
8 - Idem 5 + 7 & $7,11 \mathrm{a}$ & $0,84 \mathrm{a}$ & $44,30 \mathrm{a}$ \\
9 - Idem 6 + 7 & $7,61 \mathrm{a}$ & $0,90 \mathrm{a}$ & $43,09 \mathrm{a}$ \\
10 - Idem 6 + 10ppm de AG3 e 15ppm 2,4-D em maio & $8,14 \mathrm{a}$ & $0,83 \mathrm{a}$ & $44,78 \mathrm{a}$ \\
11 - Idem 9 + 10ppm de AG3 e 15ppm 2,4-D em maio & $7,86 \mathrm{a}$ & $0,93 \mathrm{a}$ & $47,16 \mathrm{a}$ \\
Média & 7,65 & 0,87 & 45,46 \\
Coeficiente de Variação (\%) & 9,36 & 9,56 & 6,64 \\
\hline
\end{tabular}

*Médias não seguidas por mesma letra, na coluna, diferem entre si, pelo teste de Duncan, em nível de $5 \%$ de probabilidade de erro.
Entretanto, a incisão anelar aplicada em conjunto com cinco ppm de $\mathrm{AG}_{3}$ e $15 \mathrm{ppm}$ de 2,4-D (tratamento T6) não diferiu estatisticamente da testemunha, em relação à produção de frutos (tabela 1). Esse resultado não pode ser justificado, pois, tanto o uso de $\mathrm{AG}_{3}$ (tratamento T2) como a incisão anelar (tratamento T3), aumentaram a produção de frutos quando aplicados separadamente. Descarta-se a hipótese de um efeito fitotóxico cumulativo, pois, caso contrário o mesmo deveria ter-se manifestado também nos tratamentos subseqüentes.

A aplicação de 10ppm de $\mathrm{AG}_{3}$ e 15ppm de 2,4-D em maio não exerceu efeito significativo sobre a fixação de frutos, discordando dos resultados obtidos por RAGONE (1992) e SCHÄFER et al. (1999), os quais descrevem que se pode aumentar a produtividade de laranjeiras, prevenindo a queda de pré-colheita, com a pulverização destes reguladores de crescimento. A resposta dos reguladores de crescimento nesta época pode estar relacionada a fatores climáticos, que variam de ano para ano.

$\mathrm{Na}$ tabela 2 observa-se que não há diferenças estatisticamente significativas entre as características químicas e físicas dos frutos avaliadas. $\mathrm{O}$ teor de suco variou de 43,09 a $47,16 \%$. Esses resultados estão de acordo com os apresentados por COELHO et al. (1978), os quais citam que a combinação de épocas de aplicação, de $\mathrm{AG}_{3}$ e 2,4-D, em tangerineira 'Cravo' não diferenciaram a percentagem de suco produzida, e com EMBLETON $\boldsymbol{e t}$ al. (1973) que, com ou sem a aplicação de $\mathrm{AG}_{3}$ em laranjeiras 'Valência', não observaram diferenças significativas entre os tratamentos para essa característica. O teor de SST não diferiu estatisticamente da testemunha o que está de acordo com o apresentado por COELHO et al. (1978). Entretanto EMBLETON et al. (1973) acharam diferenças altamente significativas em laranjeiras 'Valência' no teor de SST e na acidez 
titulável, o que não foi constatado neste experimento. Os resultados encontrados são justificáveis, pois o $\mathrm{AG}_{3}$ e 2,4-D retardam a degradação da clorofila nos frutos e aumentam a retenção dos mesmos, mas isto não afeta suas características físico-químicas.

Quanto à percentagem de suco, as diferenças estatisticamente não significativas entre os tratamentos são justificáveis pelo fato dos fitorreguladores e incisão anelar auxiliarem o crescimento e desenvolvimento das vesículas de suco nos frutos, principalmente na fase II de desenvolvimento destes (AGUSTÍ \& ALMELA, 1991). No tratamento testemunha, este efeito ocorre devido a uma maior distribuição dos fotoassimilados para um menor número de frutos fixados. $\mathrm{O}$ peso médio dos frutos também realça isso, pois não mostrou diferenças significativas, comprovando que a planta, auxiliada pela aplicação de fitorreguladores e incisão anelar dos ramos, conseguiu suprir adequadamente as necessidades dos frutos, conseqüentemente não afetando o peso médio e o teor de suco destes.

\section{CONCLUSÕES}

A aplicação de cinco ppm de $\mathrm{AG}_{3}$, no final da queda das pétalas, bem como a incisão anelar, 10 dias após a floração, ou 15ppm de 2,4-D em novembro aumentaram o peso de frutos produzidos por laranjeiras de umbigo 'Monte Parnaso'. No entanto, a aplicação de fitorreguladores e/ou incisão anelar dos ramos principais não afetou o peso médio, o teor de sólidos solúveis totais, a acidez total titulável e a percentagem de suco dos frutos das laranjeiras.

\section{REFERÊNCIAS BIBLIOGRÁFICAS}

AGUSTÍ, M., ALMELA, V. Aplicación de fitorreguladores en citricultura. Barcelona : Aedos, 1991. 169p.

AGUSTÍ, M.F., ALMELA, V.O., AZNAR, M.A. Citros: desenvolvimento e tamanho final do fruto. Porto Alegre : Ivo Manica, 1996. 102p.

COELHO, Y.S., DUARTE, C.S., CHITARRA, M.I.F., et al. Ácido giberélico e 2,4-D em citros. II. Efeitos na maturação da tangerina 'Cravo' (Citrus reticulata Blanco). Revista Brasileira de Fruticultura, Cruz das Almas, v.1, n.2, p.3144, 1978.
EL-OTMANI, M. Usos principais de reguladores de crescimento na produção de citros. In: SEMINÁRIO INTERNACIONAL DE CITROS: FISIOLOGIA, 2, 1992, Bebedouro-SP. Anais... Campinas, SP : Fundação Cargill, 1992. 226p., p.43-51.

EMBLETON, T.W., JONES, W.W., COGGINS JR.C.W. Aggregate effects of nutrients and gibberellic acid on 'Valencia' orange crop value. Journal American Society for Horticultural Science, Alexandria, v.98, n.3, p.281-285, 1973.

FAO. Oranges. Tangerines, mandarins, clementines and satsumas. Lemons and limes. Grapefruit and pomelos. Production yearbook, Roma, v.52, p.157-160, 1998.

IBGE. Produção Vegetal. Agricultura: laranja, limão e tangerina. Anuário Estatístico do Brasil, Rio de Janeiro, v.56, p.3-34, 3-35 e 3-38, 1996.

KOLLER, O.C. Laranjeira de umbigo: aumento de produtividade. Jornal do comércio, Porto Alegre, 23/12/93, Suplemento Rural, p.4. 1993.

KOLLER, O.C., FERRARI SOBRINHO, F., SCHWARZ, S.F. Frutificação precoce de laranjeiras 'Monte Parnaso' com anelagem e pulverizações de ácido giberélico e óleo mineral. Pesquisa Agropecuária Brasileira, Brasília, v.34, n.1, 9, 63 68, 1999a.

KOLLER, O.C., SCHÄFER, G., SARTORI, I.A., et al. Efeito da anelagem, fitorreguladores e fungicidas sobre a fixação de frutos na laranjeira 'Monte Parnaso'. Revista Brasileira de Fruticultura, Jaboticabal, v.21, n.1, p.70-73, 1999b.

MOSS, G.I. Promoting fruit-set and yield in sweet orange. Australian Journal Experimental Agriculture, Melbourn, v.114, p.96-102, 1972.

PRIMO-MILLO, E. Regulacion del cuajado del fruto en los citricos. In: CONGRESO DE CITRICULTURA DE LA PLANA, 1, 1993, Nules, Espanha. Anais... Valência : Ajunta de Nules, 1993. 291p. p.57-74.

RAGONE M.L. Os reguladores de crescimento no cultivo cítrico da Argentina. In: SEMINÁRIO INTERNACIONAL DE CITROS: FISIOLOGIA, 2, 1992, Bebedouro-SP. Anais... Campinas, SP : Fundação Cargill, 1992. 226p. p.52-66.

SCHÄFER G., KOLLER O.C., SARTORI I.A. Retenção de frutos de laranjeiras de umbigo 'Monte Parnaso' em função da aplicação de 2,4-D, ácido giberélico e da anelagem de ramos. Ciência Rural, Santa Maria, RS, v.29, n.4, p.639644, 1999.

ZUCCONI, F., MONSELISE, S.P., GOREN, R. Growth abscission relationships in developing orange fruit. Scientia horticulturae, v.9, p.137-146, 1978.

Ciência Rural, v. 31, n. 4, 2001. 